Article

\title{
Investigation of Laser Power Output and Its Effect on Raman Spectrum for Marine Metal Corrosion Cleaning
}

\author{
Haoting Liu ${ }^{1, *} \mathbb{C}$, Yafei Xue ${ }^{2, *}$, Jiacheng $\mathrm{Li}^{1}{ }^{1}$, Weijie $\mathrm{Wu}^{1}$ and Jinhui Lan ${ }^{1}$ \\ 1 Beijing Engineering Research Center of Industrial Spectrum Imaging, School of Automation and Electrical \\ Engineering, University of Science and Technology Beijing, Beijing 100083, China; yyca_2015@sina.com (J.L.); \\ wuweijie@protonmail.com (W.W.); jinhuilan@protonmail.com (J.L.) \\ 2 Guangdong Provincial Key Laboratory of Advanced Welding Technology, China-Ukraine E. O. Paton \\ Institute of Welding, Guangdong Welding Institute, Guangzhou 510650, China \\ * Correspondence: liuhaoting@ustb.edu.cn (H.L.); xuebo@protonmail.com (Y.X.); \\ Tel.: +86-020-6108-6768 (H.L. \& Y.X.)
}

Received: 2 November 2019; Accepted: 9 December 2019; Published: 18 December 2019

\begin{abstract}
The relationship between the laser power output and its effect on Raman spectrum is investigated for a laser cleaning application of marine metal corrosion processing. First, an image feature based on a corrosion degree evaluation is implemented before cleaning. The image features include texture coarseness, texture entropy, texture intensity, texture contrast, the texture's cluster degree, and texture homogeneity. To decrease the image feature dimension for a convenient application, the Analytic Hierarchy Process (AHP) method is used to estimate the weight of each feature. Then the linear weighted sum of image features can be computed to get only one evaluation result. Second, a series of laser power outputs are implemented for the cleaning application under a typical corrosion degree. Then the analysis results of Raman spectrum can be obtained. The analyzed spectrum results include the corrosion components and their contents. Lastly, the relationship between laser power output and Raman spectrum under a typical initial corrosion degree can be constructed. This research study can build the prediction result of the cleaning effect map for the workpiece and guide the secondary processing of metal surface cleaning.
\end{abstract}

Keywords: laser cleaning; image feature; Raman spectrum; corrosion evaluation; laser power

\section{Introduction}

With the rapid advancement of information technology, the laser cleaning technique [1] is currently at its intelligent development stage. The intelligent laser cleaning technology utilizes multiple sensors to monitor the cleaning process [2] and controls the output energy of the laser. Therefore, the cleaning efficiency and effect [3] can be improved. Figure 1 shows the sketch map of a kind of intelligent laser cleaning system. In Figure 1, the intelligent laser cleaning system includes, at minimum, three parts: the laser and its optic path, the cleaning effect perception sensor, and the motion control guideway [4]. In general, the laser and its optic path include the laser, the beam expander and collimator, and the scanning mirrors. The cleaning effect perception sensor is always designed by an imaging sensor because of its capture ability for rich details [5]. Lastly, both the laser and the imaging sensor are installed in an electronic movement guideway. Then their working distance from the workpiece can be controlled automatically. When designing the intelligent cleaning method, some difficulties still exist. For example, regarding the imaging sensor, its imaging perception ability [6] of the metal surface state will create a great influence on the working effect of the laser. As for the laser, what kind of cleaning effect can be achieved should be investigated for a typical cleaning application. 


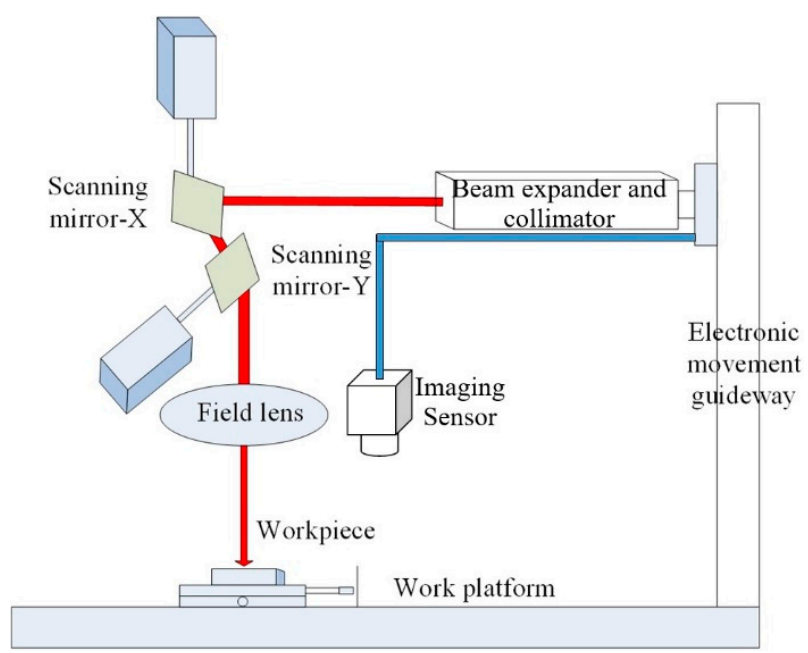

Figure 1. The sketch map of an intelligent laser cleaning system.

Some excited technique challenges can be researched in the field of an intelligent laser cleaning application. First, the corrosion degree evaluation before laser cleaning should be studied. Apparently, the final cleaning effect is related to the initial corrosion state of the metal. The corrosion components, the corrosion thickness, and the corrosion distribution [7] will all affect the cleaning effect. Thus, it is necessary to assess it before implementing laser cleaning. Second, the dynamic parameters' tuning of the laser should be researched. That means the adaptive tuning of laser process parameters, according to the changes of the corrosion state during the cleaning process, should be studied. Third, the cleaning effect evaluation after laser cleaning should also be investigated. The developments of the multi-function and mini-type sensor [8] and its data processing method are major topics in this research field. In this paper, because most of commercial laser cleaning machines do not open their functions of dynamic laser parameter tuning, we only focus on the new technique developments of the initial corrosion state evaluation using image data and building the relationship between the laser power output and the analyzed result of Raman spectrum [9]. The Raman spectrum is considered in this case because it can analyze the component and the content of corrosion metal, which has an important application value [10] in engineering.

Many research works have been done to improve the intelligent degree of the laser-related processing method. In Reference [11], a selective laser melting process was proposed. The external sensors were used to detect the working state of the production process. In Reference [12], the transient thermos-optical effects in protective windows for selective laser melting were analyzed. The temperature distribution was simulated for different scanning strategies and orders of exposure. In addition, in Reference [13], the acoustic signal detection technique was used to assist the monitor of laser welding for the cold-rolled steel strip application. The microphone arrays were utilized in that research work. After a comparable study, it can be found that previous methods have achieved many successful applications. However, some problems still exist. For example, on one hand, although the machine learning-based method can be used to improve the intelligent degree of the laser cleaning machine. The training data still create great influence on its processing effect [14]. Regarding the commercial laser cleaning product, the adjustable parameters are limited, which will greatly influence the training effect of the machine learning-based algorithm. On the other hand, the extensive adoption of image features for the corrosion degree analysis or the cleaning effect evaluation will create confusion for workers. After all, they are not the experts of image processing.

In this paper, we mainly consider the corrosion cleaning problem of a kind of carbon steel, which is widely utilized in the marine application in China, such as the building of a ship or a boat. It is also supposed that the surface lacquer of carbon steel has exfoliated naturally. Even some lacquers still exist in the metal surface. They can be removed easily by simple tools. Table 1 shows the corresponding components and their contents of carbon steel in our application. For the sake of simpleness, it is 
thought that the generation reason of the corrosion layer comes from the integrated effects of the sun light, the rain, the wind, and especially the seawater. The function time of these factors is about several months. As a result, the thickness of the corrosion layer can reach 4-6 $\mu \mathrm{m}$ or $6-8 \mu \mathrm{m}$. Its distribution is always uniform. Figure 2 shows the corrosion photo samples of our application. Figure 2a shows the macroscopic visible light image of the corrosion metal in a ship shell, the photography distance is about $10.0 \mathrm{~cm}$, and the photography environment is a sunny day. Figure $2 \mathrm{~b}-\mathrm{f}$ are the imaging results of 10, 20, 30, 40, and 50 times magnification of Figure 2a, respectively. From Figure 2, it can be seen that some big variegated textures can be observed from the metal surface easily because the marine corrosion belongs to a kind of electrochemical corrosion, which always destroys the passive film of the metal surface. In order to further decrease the analysis complexity, we suppose the observed metal is flat. For example, if the ship or the boat is big enough, this hypothesis can be accepted. The working distance between the laser device and the ship shell can be measured by a laser rangefinder or other shape scanning device.

Table 1. The components and their contents of a kind of carbon steel.

\begin{tabular}{cccccc}
\hline C & Si & Mn & S & P & Fe \\
\hline 0.14 & 0.13 & 0.44 & 0.031 & 0.015 & 0.244 \\
\hline
\end{tabular}

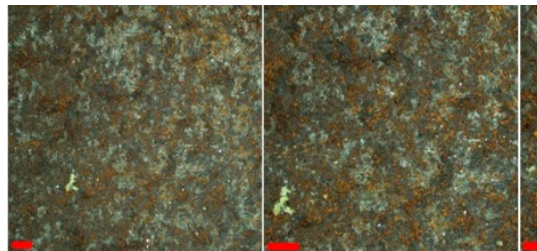

(a) (b)

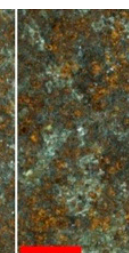

(c)

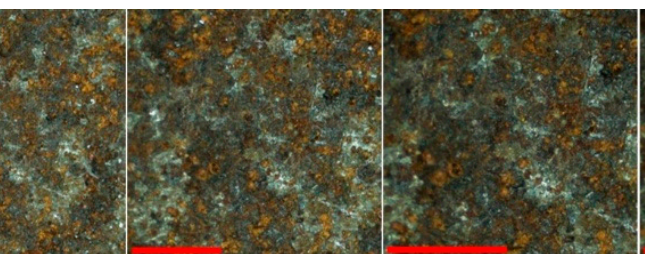

(d) (e)

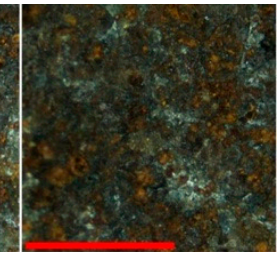

(f)

Figure 2. The corrosion photo samples of a kind of carbon steel, where the red line is the scale bar, and 1 scale bar equals $1.0 \mathrm{~mm}$. (a) is a visible light image; (b-f) are 10, 20, 30, 40, and 50 times magnification of (a), respectively.

To realize the intelligent cleaning to some extent, the following processing steps are employed in this paper. First, an image feature analysis-based corrosion degree evaluation is proposed. A visible light camera is used to capture the corresponding image data. The computed image features include texture coarseness [15], texture entropy [16], texture intensity, texture contrast [17], the texture's cluster degree [18], and texture homogeneity [19]. The Analytic Hierarchy Process (AHP) method [20] is used to decrease the dimension of the image feature vector above. The importance weights of AHP can be proposed by the system user. The AHP is considered in this case to reduce the application complexity of the image feature for the system user. Only one evaluation result is obtained after the linear weighted sum computation of image features. Second, the typical power outputs of the laser [21] are performed under the initial corrosion degrees above. Then the analysis results of Raman spectrum can be gotten. The analysis results of Raman spectrum [22] include the corrosion components and their corresponding contents. Lastly, the relationship between the typical laser power output and the analysis result of Raman spectrum can be constructed. These relationships above can be used to build the prediction result of the cleaning effect map for the workpiece and guide the secondary cleaning [23].

The main contributions of this paper include a kind of image analysis-based corrosion assessment method before laser cleaning is proposed. The multiple image texture features together with the AHP method are considered in this scenario. Second, the relationships among the initial corrosion state, the laser power output, and the Raman spectrum are investigated. The corrosion components and their corresponding contents under a typical initial corrosion state after cleaning are disclosed. Third, the practical application of the proposed method is illustrated. The advantages and the disadvantages of the proposed technique are also discussed. 
In the following sections, the proposed image feature computation and the Raman spectrum analysis methods will be presented. In addition, experiment results will be shown. Lastly, some discussions and analysis results will also be illustrated.

\section{Image Feature and Raman Spectrum Analysis Methodologies}

\subsection{Image Feature Analysis Methodology}

When assessing the metal corrosion state, the corrosion rate [24] is the most interested index. Generally, this index can be measured by the weight measurement or the component analysis method. However, it cannot represent the corrosion appearance vividly. In practical terms, a more familiar evaluation, which is preferred by the engineering department, is the method of appearance observation. Table 2 shows one of the most commonly used corrosion degree description methods in many Chinese factories. In Table 2, the corrosion state is classified into four degrees. Clearly, the imaging analysis can be used for the corrosion degree evaluation [25]. From Table 2, regarding the corrosion degree A, almost no corrosion happens. Thus, it is not necessary to carry out any laser cleaning operations. In addition, as for the corrosion degree $\mathrm{D}$, the serious corrosion occurs. In that situation, this carbon steel will be scrapped by the marine industrial department. After all, the navigation safety is the most important thing. Lastly, only two kinds of corrosion degrees are left, which should experience the laser cleaning processing. Regarding the corrosion degree $\mathrm{B}$, the thin corrosion layer can be observed throughout the metal surface because the erosion time of the external environment is not long and most of the initial oxide layers can protect the metal substrate to some extent. From the imaging point of view, only the small textures can be found in the metal surface. As for the corrosion degree $C$, some large corrosion blocks begin to appear and the initial oxide layers fall off. As a result, some big textures can be observed in the captured image.

Table 2. The description method of the corrosion degree.

\begin{tabular}{|c|c|c|}
\hline Corrosion Degree & Description & Image Example \\
\hline A & $\begin{array}{l}\text { The metal is covered by the oxide layer and } \\
\text { almost no corrosion component can be found. }\end{array}$ & \\
\hline B & $\begin{array}{l}\text { The corrosion has happened, parts of the oxide } \\
\text { layer have fallen off, and some small corrosion } \\
\text { blocks can be observed. }\end{array}$ & \\
\hline $\mathrm{C}$ & $\begin{array}{l}\text { The oxide layer has fallen off and many big } \\
\text { corrosion blocks can be observed. }\end{array}$ & \\
\hline $\mathrm{D}$ & $\begin{array}{c}\text { The oxide layer has fallen off completely. } \\
\text { The corrosion layer has covered the metal } \\
\text { surface completely. }\end{array}$ & \\
\hline
\end{tabular}

In this paper, many image features including the texture coarseness, the texture entropy, the texture intensity, the texture contrast, the texture cluster degree, and the texture homogeneity are used to assess the corrosion degree. First, the Tamura coarseness is used to compute the texture coarseness. Its computation method is shown by Equations (1) and (2). The Tamura coarseness presents the refinement degree of the image texture. The larger the value of Tamura coarseness is, the rougher the image texture would be. Second, the Gray-Level Co-Occurrence Matrix (GLCM) is computed. The GLCM entropy, the GLCM contrast, the GLCM cluster prominence, and the GLCM homogeneity 
are all utilized. Equations (3)-(6) show their computational methods. The GLCM entropy represents the chaos degree of the image texture. The larger the entropy is, the bigger the chaos degree would be. The GLCM contrast indicates the definition of image texture and its depth. The larger the contrast is, the clearer the texture would be. The GLCM cluster prominence describes the distinguishment of different texture types. The larger the cluster prominence is, the bigger the texture difference would be. In addition, the GLCM homogeneity means the local uniformity. The larger the homogeneity is, the better the local uniformity would be. Additionally, the GLCM features in $0^{\circ}, 45^{\circ}, 90^{\circ}$, and $135^{\circ}$ are all considered in this paper. Lastly, the arithmetic average of the image intensity is employed to assess the texture intensity of the metal image. Equation (7) shows its computational method. Clearly, the image intensity can represent the color of the corrosion component to some extent.

$$
\begin{gathered}
M_{T_{-} \text {Coa }}=\frac{1}{M \times N} \sum_{i} \sum_{j} S_{\text {opt }}(i, j) \\
S_{\text {opt }}(i, j)=2^{k} \\
M_{G_{-} \text {Ent }}^{+}=\sum_{i} \sum_{j} G(i, j) \log _{2} G(i, j) \\
M_{G_{-} \text {Con }}^{+}=\sum_{i} \sum_{j}(i-j)^{2} G(i, j) \\
M_{G_{-} \text {Prom }}^{+}=\sum_{i} \sum_{j}\left(i+j-\mu_{x}-\mu_{y}\right)^{4} G(i, j) \\
M_{G_{-} \text {Hom }}^{\dagger}=\sum_{i} \sum_{j} \frac{1}{1+(i-j)^{2}} G(i, j) \\
M_{\text {Int }}=\sum_{i} \sum_{j} I(i, j)
\end{gathered}
$$

where $S_{\text {opt }}(i, j)$ is an optimal function for each pixel when $k$ can maximize the average intensity difference in the horizontal and the vertical directions, $M$ and $N$ are the width and the height of the image block, respectively, $G(i, j)$ is a normalized gray tone of the spatial-dependence matrix, $\mu_{x}$ and $\mu_{y}$ are the mean values of $p_{x}$ and $p_{y}, p_{x}=\sum_{j=1}{ }^{K} G(i, j), p_{y}=\Sigma_{i=1}{ }^{K} G(i, j), K$ is the gray degree, $I(i, j)$ is the image intensity in pixel position $(i, j)$, and symbol " + " can be chosen by $0^{\circ}, 45^{\circ}, 90^{\circ}$, and $135^{\circ}$, respectively.

After the computations above, six image features can be obtained. However, they are difficult for use in practice. One on hand, it will be very hard to evaluate the corrosion degree by using six criteria simultaneously. The users have to build six different distribution regulations for them. On the other hand, the system users are also not the experts of the image feature. They cannot give out the proper evaluation results of the corrosion degree in many cases. To conquer that problem, the AHP method is used. The AHP is an operational method, which can get the importance weights by the hierarchical sorting. When implementing the AHP computation, first, the hierarchical model will be built for the typical application. Figure 3 shows the AHP model for our application. Six image features are classified into three groups, according to their functions. Second, the evaluation matrixes will be constructed. Table 3 shows the evaluation criterion of AHP. Apart from other methods, the construction of the AHP evaluation matrix needs to compare the importance between any two factors. Third, the eigenvector matrix will be calculated for the evaluation matrix above, and the hierarchy single ranking and its uniformity inspection can be performed. Lastly, the hierarchy general ranking and the uniformity inspection will be implemented. In this paper, the initial importance comparisons between any two image features are given by the opinions of image processing experts or system users. 
Then, after the computation of AHP, the weights of each image feature can be obtained. Lastly, a final evaluation index can be computed by using Equations (8) and (9).

$$
\begin{gathered}
M_{*}^{\text {Ave }}=\frac{1}{4}\left[M_{*}^{0}+M_{*}^{45}+M_{*}^{90}+M_{*}^{135}\right] \\
M_{\text {Img }}=w_{1} \times M_{T_{-} C o a}+w_{2} \times M_{G_{-} E n t}^{\text {Ave }}+w_{3} \times M_{\text {Int }}+w_{4} \times M_{G_{-} \text {Con }}^{\text {Ave }}+w_{5} \times M_{G_{-} \text {Prom }}^{\text {Ave }}+w_{6} \times M_{G_{-} \text {Hom }}^{\text {Ave }}
\end{gathered}
$$

where $M_{*}{ }^{0}, M_{*}{ }^{45}, M_{*}{ }^{90}$, and $M_{*}{ }^{135}$ are the GLCM features of Equations (3)-(6) in the directions of $0^{\circ}$, $45^{\circ}, 90^{\circ}$, and $135^{\circ}$, respectively, and the symbol "*” can be chosen by G_Ent, G_Con, G_Prom, and G_Hom. $w_{i}(i=1,2, \ldots, 6)$ are the weights of these features above.

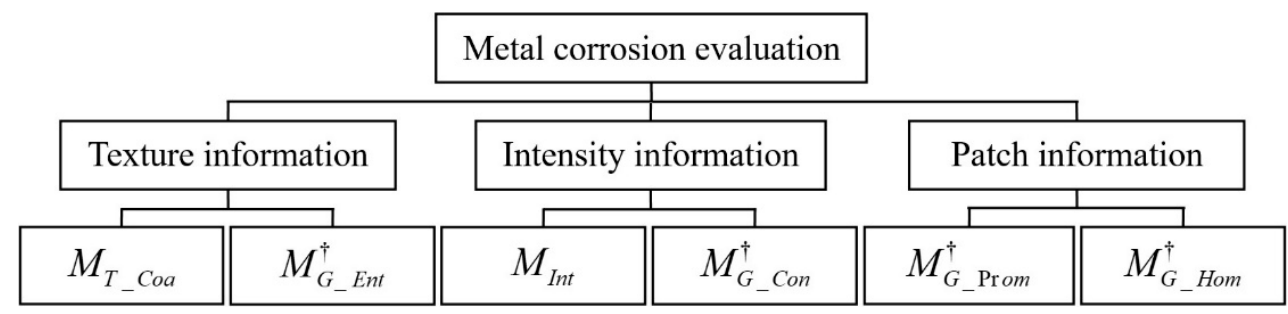

Figure 3. The structure of the Analytic Hierarchy Process (AHP) model for the metal corrosion evaluation.

Table 3. The evaluation criterion of Analytic Hierarchy Process (AHP).

\begin{tabular}{cc}
\hline Intensity of Importance & Definition \\
\hline 1 & Equally important \\
3 & Weakly important \\
5 & Essentially important \\
7 & Very strongly important \\
9 & Absolutely important \\
$2,4,6,8$ & Importance between the above odd numbers \\
\hline
\end{tabular}

\subsection{Raman Spectrum Analysis Methodology}

The Raman spectrum is a kind of analysis tool for estimating the scattering spectrum. It can measure the spectrum of scattering light, which has a different frequency with respect to the input light source, and get the vibration and the rotation information of the molecule. Then the molecule type and structure can be deduced. Comparing with the measurement method of the other spectroscopy technique, e.g., the middle infrared spectrum, the Raman-based method has strong robustness to the environmental changes. Thus, it has a wide application in the engineering site. When measuring the Raman spectrum, a calibration step, which uses a standard silicon as the reference, will be performed. Then the spectrometer will cast the typical laser beam on the surface of the sample and observe its reflection to implement the spectrum analysis. After the spectrum data collection, the measured data should be processed by some mathematical methods. In this paper, two kinds of data processing methods are considered. The first one is the baseline removal technique. The method in Reference [26] is utilized in this scenario. In Reference [26], a baseline model, which is illustrated in Equation (10) was considered. The zero-order Savitzky-Golay filter [27] was employed to estimate the baseline. Then this filter could use the local polynomial function and the least square method to estimate the baseline and extract the original signal. Equation (11) shows its polynomial function. Equation (12) presents its residual and Equation (13) illustrates its final filtering result. It should be emphasized that the computation result of the baseline correction is not always as accurate as we have expected, especially when it comes to the area estimation of the Raman peak. However, it is still helpful to identify the Raman peak from the complex measurement data. As a result, this computation step is considered in this paper.

$$
O_{\text {Raman }}(n)=\left[S_{\text {baseline }}(n)+x(n)\right] * S_{\text {blurring }}(n)+S_{\text {noise }}(n)
$$




$$
\begin{gathered}
p(n)=\sum_{k=0}^{N} a_{k} n^{k} \\
\varphi_{N}=\sum_{n=-M}^{M}[p(n)-x(n)]^{2} \\
x^{\prime}(n)=\frac{1}{2 M+1} \sum_{k=-M}^{M} C(k) x(k+n)
\end{gathered}
$$

where $O_{\text {Raman }}(n)$ is the output of the Raman spectrum device, $S_{\text {baseline }}(n)$ is the baseline of the Raman spectrum, $x(n)$ is the actual signal, $S_{\text {blurring }}(n)$ is the instrumental blurring function, $S_{\text {noise }}(n)$ is the system noise, $p(n)$ is a polynomial function, $a_{k}$ is the polynomial weight, $N$ is the item number, $\varphi_{N}$ is the residual, $x^{\prime}(n)$ is the result after filter processing, $C(k)$ is the weight of the filter, and $2 M+1$ is the size of the observation window.

The second data processing method is the content estimation of the Raman spectrum. Figure 4 shows the measurement examples of Raman spectrum before and after the laser cleaning application. It can be seen that some peaks can be observed in both Figure 4a,b. Regarding the Raman spectrum, its peak always indicates the specific component in the observed metal surface. The intensity of the peak and its corresponding area can also represent the component content [28] to some extent. Due to the existence of system noises, the content measurement of Raman is always inaccurate. In engineering, some statistical distribution functions can be used to fit the Raman peak. Then the area of the distribution function can be employed to represent the content of the typical component. From Figure 4, many distribution functions can be used here, such as the Gaussian distribution function, the Cauchy distribution function, or the Laplacian distribution function. However, only the Gaussian distribution function is used to solve the fitting problem in this paper for two reasons. Many statistical data have shown the measurement data collected from the natural environment, which always combines with the Gaussian distribution [29]. Second, our practical tests also indicate the good performance of that function in both precision and stability. Equation (14) shows the distribution function of the Gaussian distribution. In Figure 4, it should be emphasized that some Gaussian distributions overlap with each other. To analyze that spectrum, only the least amount of Gaussian function is preferred in engineering if the fitting result is accepted. In addition, if we use the Gaussian distribution function to fit a complex spectrum curve, the center position of the Gaussian function may be estimated in the decimal degree.

$$
f(x ; \sigma, \mu)=\frac{1}{\sqrt{2 \pi} \sigma} \exp ^{\left[-\frac{(x-\mu)^{2}}{2 \sigma^{2}}\right]}
$$

where $f(x ; \sigma, \mu)$ is the probability density function of the Gaussian distribution and $\sigma$ and $\mu$ are its parameters.

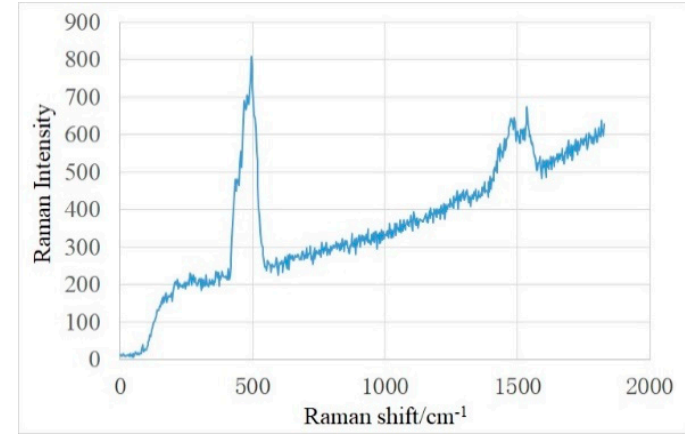

(a)

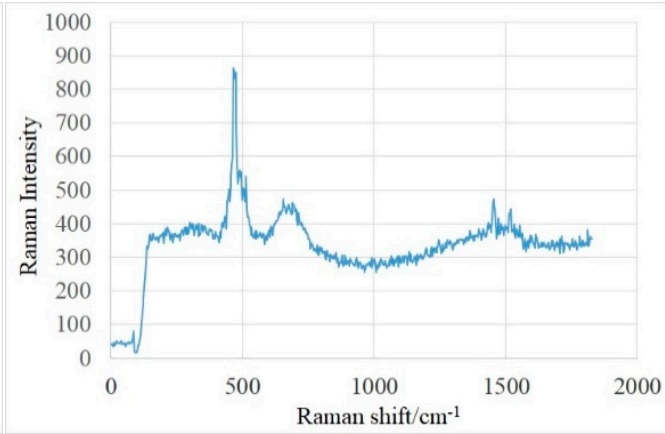

(b)

Figure 4. The examples of the Raman spectrum (a) before and (b) after laser cleaning . 


\section{Experiments and Results}

A series of experiments are implemented to test the validity of the proposed method. The relationships between the laser power output and the Raman spectrum are also investigated. All the simulation programs are written by C (Microsoft Visual Studio free version, Washington, DC, USA) in our PC (4.0 GB RAM, 1.70GHz Intel (R) Core (TM) i3-4005U CPU, Lenovo, Beijing, China).

\subsection{Experimental System and Data}

Figure 5 shows the photos of the experiment system and the corresponding image data. Figure 5a shows the photo of the laser in the laser cleaning device. Figure $5 b$ shows the photo of a visible light camera (including both the sensor and the lens) while Figure $5 c$ presents the photo of the Raman spectrometer. Figure $5 \mathrm{~d}$ gives out the photo of corrosive metal before and after cleaning. Figure 5a shows a YLP-HP-10-30× 400-20-200 pulsed laser, which is made by the IPG company in German. Its maximum average output power is about $200 \mathrm{~W}$. Its working distance between the output port of the laser and the metal sample is about $222 \mathrm{~mm}$. Its working frequency is $20 \mathrm{KHz}$, its pulse width is $60 \mathrm{ns,}$ its single pulse energy is $3.99 \mathrm{~mJ}$, and its line space is $0.05 \mathrm{~mm}$. Figure $5 \mathrm{~b}$ shows an industrial camera which is made by Daheng company in China; while Figure 5c presents an Invia confocal-micro-Raman spectrometer, which is made by the Renishaw company in United Kingdom. Figure 5d shows the image captured by the camera. In Figure 5b, the left two data are the images before laser cleaning. Some corrosion components can be observed in them and the right two data are the images after cleaning. Tables 4-6 present the principle parameters of the laser, the visible light camera, and the Raman spectrometer, respectively. When using the Raman spectrometer, its laser power is set by $10 \%$ of its maximum output, the amplification of objective lens is 50 times, its scan scope is $100-1800 \mathrm{~cm}^{-1}$, its scan step is $2.5 \mathrm{~cm}^{-1}$, and its integration time is $20.0 \mathrm{~s}$. The environmental light will create some negative effects on the image data. Thus, only the gray images are captured in this experiment. The standard histogram equalization method is used to preprocess the image data before they are saved.

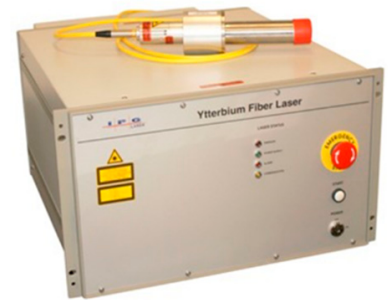

(a)

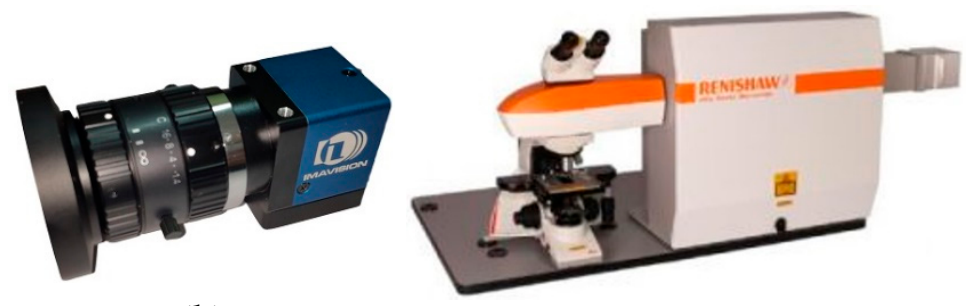

(b)

(c)

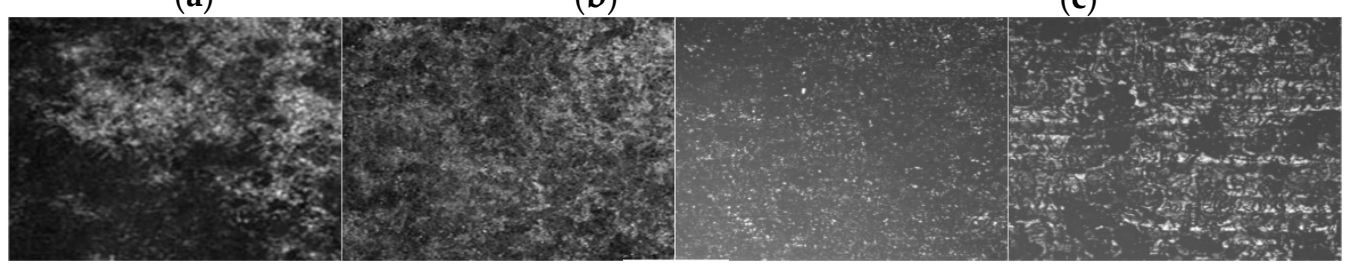

(d)

Figure 5. The photos of the experimental system and the image data samples. (a) is the laser in the laser cleaning device; (b) is the visible light camera; (c) is the Raman spectrometer; (d) is the corrosion metal images before and after cleaning.

Table 4. The principle parameters of the laser.

\begin{tabular}{cccc}
\hline $\begin{array}{c}\text { Maximum Average } \\
\text { Output Power (W) }\end{array}$ & $\begin{array}{c}\text { Central Emission } \\
\text { Wavelength (nm) }\end{array}$ & $\begin{array}{c}\text { Emission } \\
\text { Bandwidth (nm) }\end{array}$ & $\begin{array}{c}\text { Pulsed } \\
\text { Energy (mJ) }\end{array}$ \\
\hline $190-210$ & $1055-1075$ & $5-10$ & 10 \\
\hline $\begin{array}{c}\text { Pulse Repetition } \\
\text { Rate (kHz) }\end{array}$ & $\begin{array}{c}\text { Pulse Duration } \\
\text { Time (ns) }\end{array}$ & $\begin{array}{c}\text { Initial Output Beam } \\
\text { Diameter (mm) }\end{array}$ & Beam Quality \\
\hline $2-50$ & $30-400$ & $6-9$ & $10-14$ \\
\hline
\end{tabular}


Table 5. The principle parameters of a visible light camera.

\begin{tabular}{cccccc}
\hline Sensor Type & $\begin{array}{c}\text { Sensor Size } \\
(\boldsymbol{\mu m})\end{array}$ & $\begin{array}{c}\text { Maximum } \\
\text { Resolution }\end{array}$ & $\begin{array}{c}\text { Focal Length } \\
(\mathbf{m m})\end{array}$ & $\begin{array}{c}\text { Frame Rate } \\
(\mathbf{H z})\end{array}$ & $\begin{array}{c}\text { Working } \\
\text { Wavelength }\end{array}$ \\
\hline CMOS & $3.2 \times 3.2$ & $2048 \times 1536$ & 5.0 & 12 & $\begin{array}{c}\text { Visible light } \\
\text { waveband }\end{array}$ \\
\hline
\end{tabular}

Table 6. The principle parameters of the Raman spectrometer.

\begin{tabular}{ccc}
\hline Laser Type & Laser Wavelength $(\mathbf{n m})$ & Spatial Resolution $(\mu \mathrm{m})$ \\
\hline Argon ion laser & 514.5 & $\begin{array}{c}\text { X, Y coordinate directions 1 } \mu \mathrm{m} \\
\text { Z coordinate direction } \sim 2 \mu \mathrm{m}\end{array}$ \\
\hline Spectral Range $\left(\mathrm{cm}^{-\mathbf{1}}\right)$ & Spectral Resolution $\left(\mathrm{cm}^{-\mathbf{1}}\right)$ & Spectral Repeatability $\left(\mathrm{cm}^{\mathbf{- 1}}\right)$ \\
\hline $100-4000$ & 1 & $\leq 0.1$ \\
\hline
\end{tabular}

\subsection{Results of a Corrosive Degree Evaluation}

In this paper, an image feature analysis-based corrosive degree evaluation is proposed. Table 7 shows some practical computation results of the corresponding image features. The GLCM results in $0^{\circ}$ are illustrated in this scenario. To simplify the evaluation process, AHP is used to get only one assessment index. Table 8 shows the judgmental matrix results of the AHP criteria hierarchy. Table 9 gives out the judgmental matrix results of the AHP alternative hierarchy and Table 10 is the final estimated weights of the AHP model. Then we can use the weights in Table 10 and the image feature data in Table 7 to compute the final evaluation result of the metal corrosion degree by using Equation (8). From Tables 8-10, it can be seen that, among these image feature factors, the texture coarseness plays the most important role in the corrosion degree evaluation while the texture intensity is the least important factor because their weights are 0.7124 (the maximum value) and 0.0144 (the minimum value), respectively. To assess the validity of our method, a comparison experiment is made. We compare the results of our proposed method and those of the method illustrated in Table 2. The evaluation method in Table 2 uses the subjective experience to discern the corrosion degree. A performance evaluation index is defined in Equation (15). In this experiment, 80 images before the cleaning application are utilized, where 36 images belong to the corrosion degree $\mathrm{B}$ and 44 images are the corrosion degree C. Additionally, as we have stated above, the corrosion degrees $\mathrm{A}$ and $\mathrm{D}$ need not experience laser cleaning. Thus, it is not necessary to evaluate their corrosion degrees by the image analysis-based method. After the computation, it can be found that the correct classification ratio, i.e., the index in Equation (15), can be larger than $93.375 \%$. That result indicates the validity of our proposed method to some extent.

$$
C C R=\frac{N_{\text {correct }}}{N_{\text {Total }}}
$$

where $N_{\text {Correct }}$ is the correct classification number of the corrosion degree evaluation using the feature analysis-based method. In this case, the correct classification means that the assessment result, which uses our method, has the same evaluation output with the subjective method presented in Table 2 . $N_{\text {Total }}$ means the total times of the evaluation experiment. Clearly, in this paper, $N_{\text {Total }}=36+44=80$.

Table 7. The result examples of image features.

\begin{tabular}{ccccccc}
\hline Num & $\boldsymbol{M}_{T_{-} \text {Coa }}$ & $\boldsymbol{M}_{{ }_{\text {G_Ent }}}$ & $\boldsymbol{M}_{\text {Int }}$ & $\boldsymbol{M}_{\boldsymbol{G}_{-} \text {Con }}$ & $\boldsymbol{M}_{\text {G_Prom }_{-}}$ & $\boldsymbol{M}_{\boldsymbol{G}_{-} \text {Hom }}$ \\
\hline 1 & 2.12781 & 2.811652 & 106 & 0.593458 & 187.165814 & 0.774368 \\
2 & 2.233168 & 2.583998 & 93 & 0.449418 & 678.798712 & 0.830039 \\
3 & 2.270004 & 2.470134 & 80 & 0.387261 & 849.111131 & 0.843735 \\
4 & 2.377367 & 2.649662 & 94 & 0.446554 & 880.062174 & 0.831126 \\
5 & 2.236245 & 2.762098 & 99 & 0.426323 & 204.382459 & 0.810559 \\
6 & 2.31929 & 2.758776 & 96 & 0.41641 & 212.443985 & 0.815336 \\
7 & 2.227868 & 2.749216 & 100 & 0.415732 & 227.420047 & 0.815706 \\
8 & 2.299521 & 2.740829 & 93 & 0.415828 & 247.127022 & 0.818207 \\
9 & 2.336464 & 2.747704 & 101 & 0.380215 & 244.702209 & 0.827395 \\
10 & 2.365239 & 2.72145 & 101 & 0.354979 & 243.449295 & 0.837478 \\
\hline
\end{tabular}


Table 8. The judgmental matrix results of the AHP criteria hierarchy.

\begin{tabular}{cccc}
\hline Criteria & Texture Information & Intensity Information & Patch Information \\
\hline Texture information & 1 & 9 & 9 \\
Intensity information & $1 / 9$ & 1 & $1 / 2$ \\
Patch information & $1 / 9$ & 2 & 1 \\
\hline
\end{tabular}

Table 9. The judgmental matrix results of the AHP alternative hierarchy.

\begin{tabular}{ccccccccc}
\hline Alternatives & $M_{T_{-} \text {Coa }}$ & $M_{G_{-} \text {Ent }}$ & Alternatives & $M_{\text {Int }}$ & $M_{G_{-} \text {Con }}$ & Alternatives & $M_{G_{-} \text {Prom }}$ & $M_{G_{-} H o m}$ \\
\hline$M_{T_{-} \text {Coa }}$ & 1 & 7 & $M_{I n t}$ & 1 & $1 / 4$ & $M_{G_{-} \text {Prom }}$ & 1 & 3 \\
$M_{G_{-} \text {Ent }}$ & $1 / 7$ & 1 & $M_{G_{-} \text {Con }}$ & 4 & 1 & $M_{G_{-} \text {Hom }}$ & $1 / 3$ & 1 \\
\hline
\end{tabular}

Table 10. The final estimated importance weights of the AHP model.

\begin{tabular}{ccccccc}
\hline Name & $M_{T_{-} \text {Coa }}$ & $M_{G_{-} \text {Ent }}$ & $M_{\text {Int }}$ & $M_{G_{-} \text {Con }}$ & $M_{G_{-} \text {Prom }}$ & $M_{G_{-} \text {Hom }}$ \\
\hline Value & 0.7124 & 0.1018 & 0.0144 & 0.0574 & 0.0855 & 0.0285 \\
\hline
\end{tabular}

The imaging analysis of the metal corrosion degree before cleaning is necessary for the development of an intelligent laser cleaning technique. First, it can provide an objective evaluation result for corrosive metal. Traditionally, the corrosion degree evaluation is always implemented by the method presented in Table 2. The workers will decide the corrosion degree by their personal experiences. Clearly, the proposed method can give a stable evaluation result comparing the subjective method above. Second, the proposed method can save the image, which can be used as a product quality dataset. Third, the image-based method can discern some details that humans cannot percept, which indicates a better evaluation precision. After the tests of a series of experiments, some experience distributions of the evaluation index $M_{I m g}$ can be deduced. Regarding the marine corrosive metal, the $M_{I m g}$ distribution of corrosion degree $B$ can be located in $[1.0,19.5]$ while the distribution of corrosion degree $C$ can be found in the scope of $(19.5,92.5]$. Currently, our image-based evaluation method also has some shortcomings. For example, during the image collection process, even though the image preprocessing methods have been utilized, the image analysis result is still affected by the environment light, the photography distance, and the magnification of the camera. To conquer these problems, on one hand, some fixed supports such as the Cartesian coordinate robot [30] can be used to control the photography state of the camera. On the other hand, some machine learning-based methods [31] can be researched in the future.

\subsection{Results of Raman Spectrum Data Processing}

In this paper, the Raman spectrometer is used to analyze the components and their contents of metal samples after laser cleaning. Figure 6 shows the corresponding results of the Raman spectrum experiment. Figure $6 \mathrm{a}, \mathrm{b}$ present the examples of Raman spectrum correction, i.e., the baseline estimation. Figure $6 c, d$ are the results of Gaussian distribution fitting of Figure $6 a, b$, respectively. Figure $6 a$ comes from the image data with the corrosion degree B and Figure $6 \mathrm{~b}$ derives from the image with the corrosion degree $\mathrm{C}$. The output powers of the laser are both $120 \mathrm{~W}$ and their energy densities are $8.493 \mathrm{~J} / \mathrm{cm}^{2}$. From Figure 6, it can be seen that the baseline estimation processing can identify most parts of the spectrum base and the Gaussian distribution can fit the spectrum peak well. Regarding the distribution fitting of the spectrum peak, whether the fitting processing is necessary is decided by the opinion of the analysis expert of the Raman spectrum. Then the area of the spectrum peak can be calculated. Clearly, many factors will influence the computation result of the spectrum peak area including the system noise and the estimation precision of the spectrum baseline. That is why most of research studies do not use the area of Raman spectrum to evaluate the component content. However, after using the chemical measurement method to analyze the component content of corrosion metal, an apparent positive correlation can be observed between the peak area of the Raman spectrum and the practical corrosion content [32]. Thus, in this paper, we still calculate the peak area as a reference to assess the laser cleaning effect. 

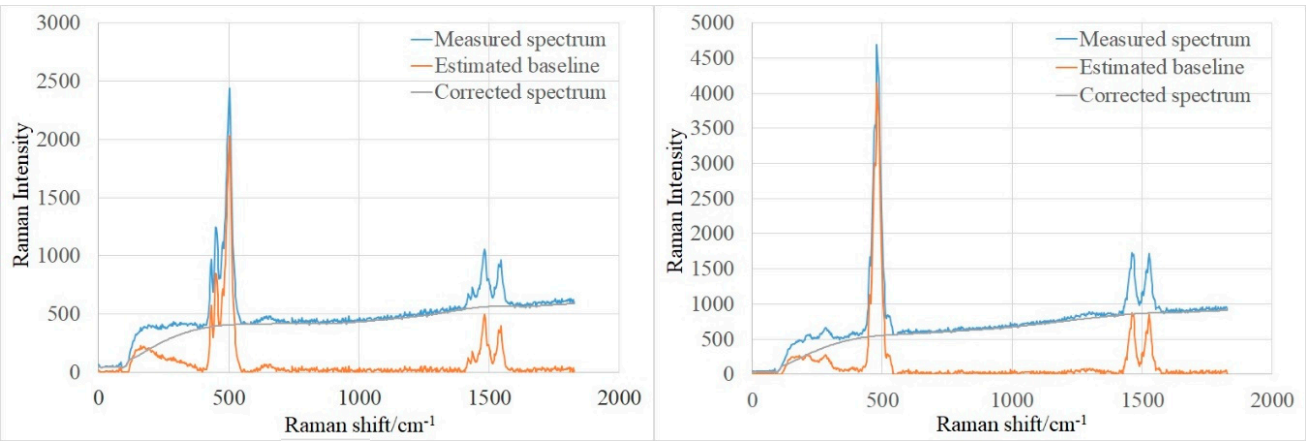

(a)
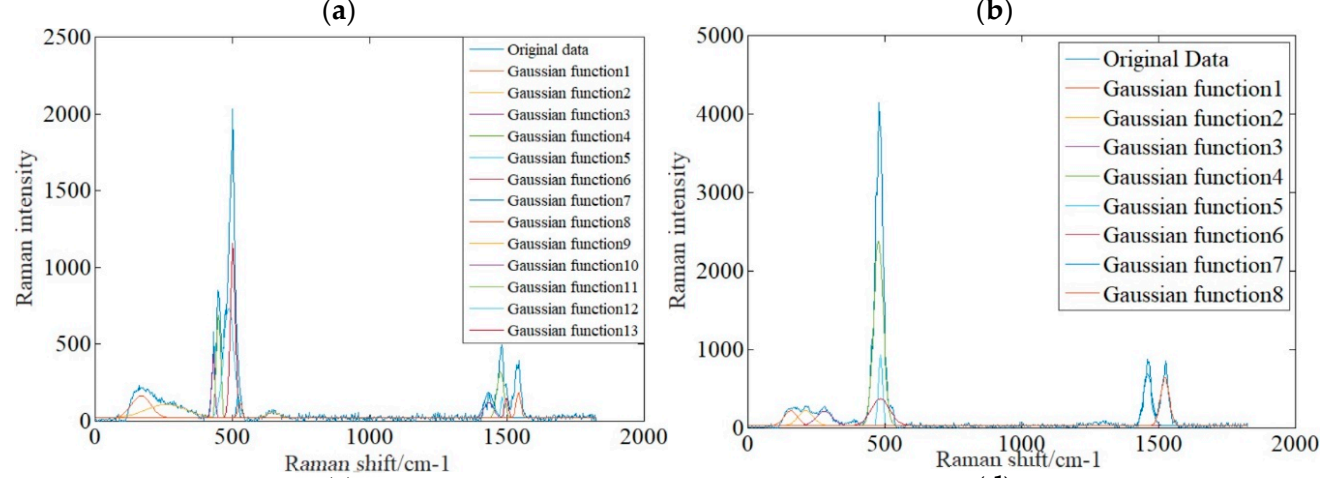

(c)

(d)

Figure 6. The results of the Raman spectrum experiment. (a) is the result of Raman spectrum baseline correction with the initial corrosion degree $\mathrm{B}$; $(\mathbf{b})$ is the result of Raman spectrum baseline correction with initial corrosion degree $C ;(\mathbf{c}, \mathbf{d})$ are the results of Gaussian distribution fitting of $(\mathbf{a}, \mathbf{b})$, respectively.

\subsection{Results of Laser Power Output and its Effect on the Raman Spectrum}

After the implementation of the laser cleaning and the Raman spectrum measurement, some relationships between the laser power and the Raman spectrum can be deduced. Figure 7 shows the corresponding results, and the main Raman peaks are marked here. In this paper, the typical laser power outputs of $80 \mathrm{~W}, 100 \mathrm{~W}, 120 \mathrm{~W}, 140 \mathrm{~W}$, and $160 \mathrm{~W}$ are investigated. Considering the laser frequency is $20 \mathrm{KHz}$ and the final laser beam radius is $150 \mu \mathrm{m}$. Thus, the energy densities of the typical power above are $5.662 \mathrm{~J} / \mathrm{cm}^{2}, 7.077 \mathrm{~J} / \mathrm{cm}^{2}, 8.493 \mathrm{~J} / \mathrm{cm}^{2}, 9.908 \mathrm{~J} / \mathrm{cm}^{2}$, and $11.323 \mathrm{~J} / \mathrm{cm}^{2}$, respectively. In the following section, we will use the energy density to represent the laser power. Figure $7 \mathrm{a}, \mathrm{b}$ are the Raman spectrum measurement results using different laser power outputs, where Figure $7 \mathrm{a}$ is the processing results using the images with corrosion degree $\mathrm{B}$, and Figure $7 \mathrm{~b}$ is the processing results using the images with corrosion degree $\mathrm{C}$. In Figure $7 \mathrm{~b}$, a sub-window with the orange dash line frame is also illustrated to show the marked results of the Raman shift. In Figure 7a,b, to improve the visualizing effects, some processing steps are performed. Regarding the vertical coordinate of each data, a series of increments, i.e., 50, 400, 100, 200, and 200 for Figure 7a and -20, 50, -100, 100, and 50 for Figure $7 \mathrm{~b}$, are added to the original data from the bottom to the top, respectively. In addition, as for the horizontal coordinate, we think the data that are less than $150 \mathrm{~cm}^{-1}$ are unreliable and the Raman peaks of the corrosion component will not occur in this region. As a result, they are not drawn here. Figure $7 \mathrm{c}$ presents the corresponding image data before laser cleaning. The first line is the images with the corrosion degree $\mathrm{B}$, and the second line is the data with the corrosion degree $\mathrm{C}$. From left to right, the imposed laser energy densities are $5.662 \mathrm{~J} / \mathrm{cm}^{2}, 7.077 \mathrm{~J} / \mathrm{cm}^{2}, 8.493 \mathrm{~J} / \mathrm{cm}^{2}, 9.908 \mathrm{~J} / \mathrm{cm}^{2}$, and $11.323 \mathrm{~J} / \mathrm{cm}^{2}$, respectively. Compared with the images in Figure $5 \mathrm{~d}$, the sizes of the image in Figure $7 \mathrm{c}$ are smaller because the Raman spectrometer can only measure the limited area (e.g., $100 \mu \mathrm{m} \times 100 \mu \mathrm{m}$ ) in the metal sample each time. From Figure 7, regarding the initial corrosion degree B, the laser energy density with $8.493 \mathrm{~J} / \mathrm{cm}^{2}$ can get a comparable good cleaning effect. As for degree C, the energy density with $9.908 \mathrm{~J} / \mathrm{cm}^{2}$ can get an ideal result. 


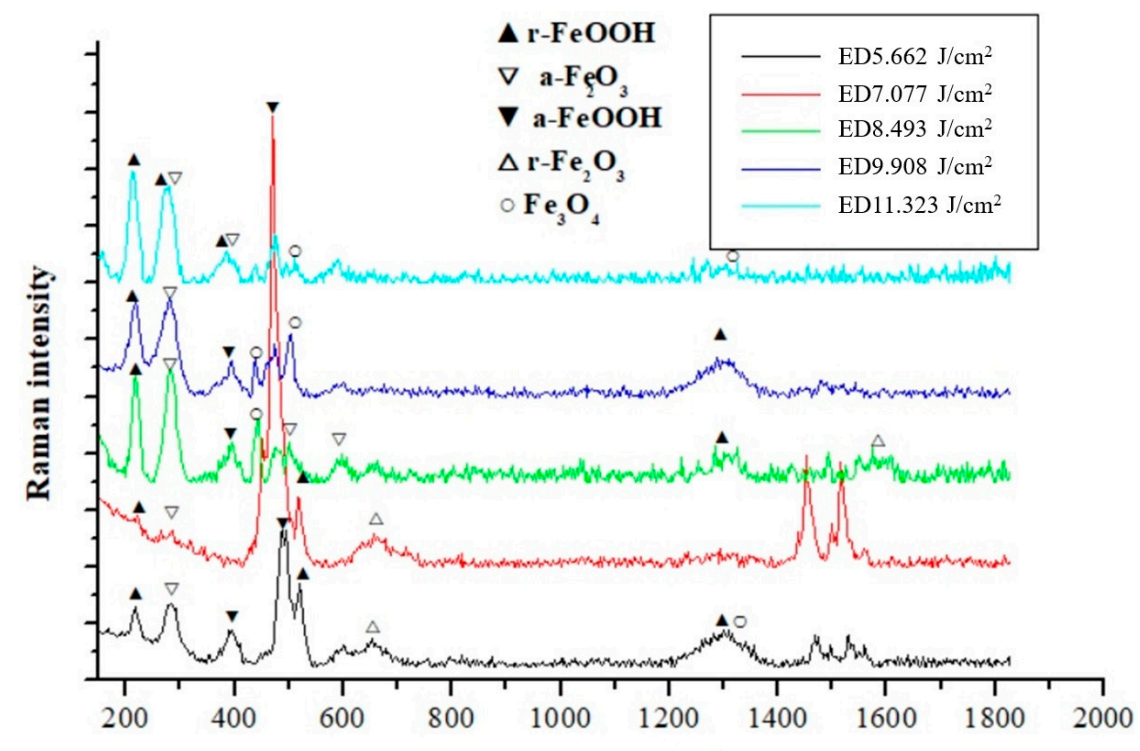

Ram an shift $/ \mathrm{cm}^{-1}$

(a)

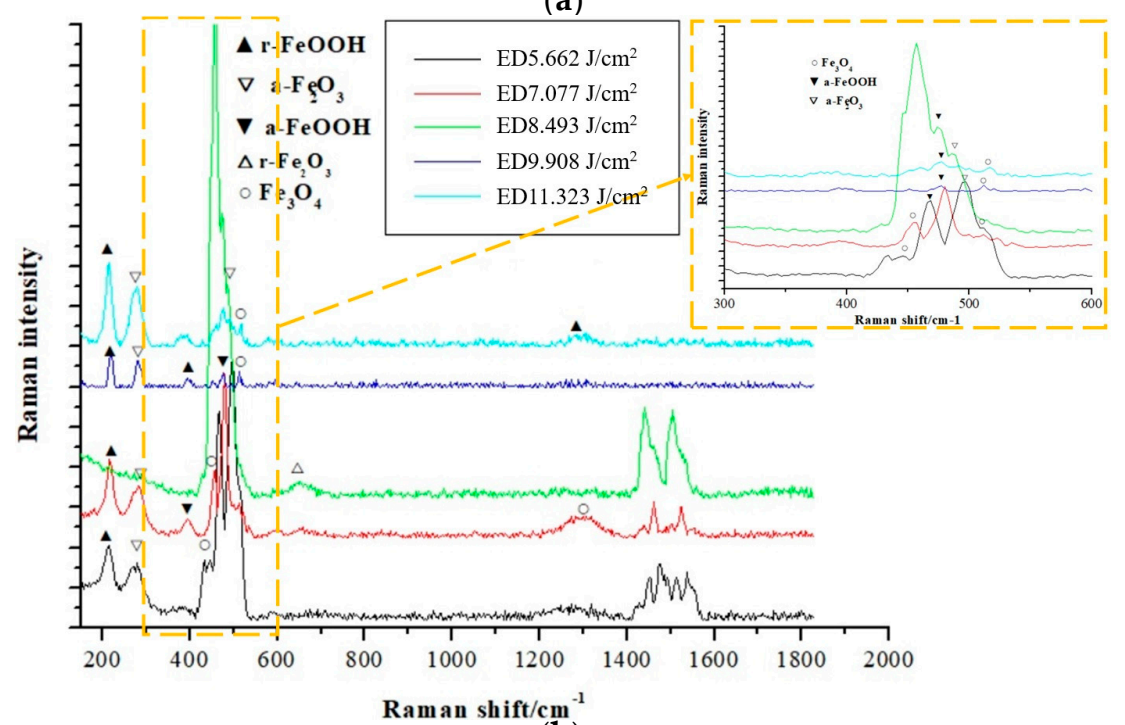

(b)

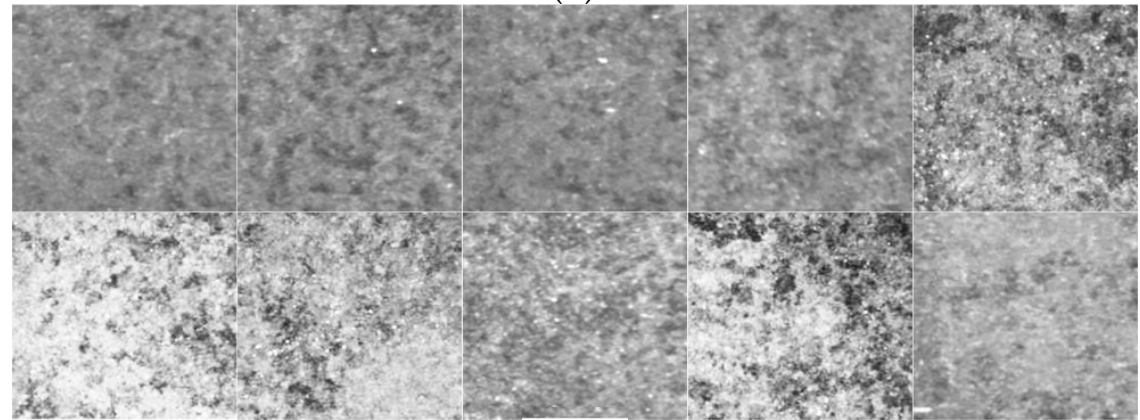

(c)

Figure 7. The relationships between the laser output power and the Raman spectrum, and the corresponding metal images before laser cleaning. The abbreviation "ED" means the energy density. (a) is the Raman spectrum comparison using the images with the initial corrosion degree B; (b) is the Raman spectrum comparison using the images with the initial corrosion degree C; (c) presents the image samples before the laser cleaning. 
Table 11 presents the typical Raman feature peaks of corrosion components, which can be found in some literatures [33]. Table 12 gives out the practical identification results of the Raman shift and their Gaussian distribution-related areas. The corresponding fitting areas are given in the brackets. From Tables 11 and 12, some change laws can be deduced. First, before laser cleaning, the main components of corrosion include $\gamma-\mathrm{FeOOH}, \alpha-\mathrm{Fe}_{2} \mathrm{O}_{3}$, and $\mathrm{Fe}_{3} \mathrm{O}_{4}$. The $\beta-\mathrm{FeOOH}$ can be observed occasionally. Second, when we carry out the laser cleaning using the energy intensity $5.662 \mathrm{~J} / \mathrm{cm}^{2}$, the peak intensities of $216 \mathrm{~cm}^{-1}$ and $281 \mathrm{~cm}^{-1}$ become bigger, and some new peaks appear in the Raman spectrum. For example, the peak shift $392 \mathrm{~cm}^{-1}$ can be observed, and its possible component is $\alpha$-FeOOH. The peak shift is $521 \mathrm{~cm}^{-1}$, and its possible component is $\gamma$-FeOOH or $\gamma-\mathrm{Fe}_{2} \mathrm{O}_{3}$. The peak shift is $282 \mathrm{~cm}^{-1}$, and its possible component is $\alpha-\mathrm{Fe}_{2} \mathrm{O}_{3}$. The peak shift is $1322 \mathrm{~cm}^{-1}$, and its possible component is $\gamma-\mathrm{FeOOH}$ or $\mathrm{Fe}_{3} \mathrm{O}_{4}$. Regarding the corresponding results above, we think the laser power is not strong enough. Only parts of the corrosion layer are exfoliated. As a result, lots of corrosion components can still be observed. Third, when the laser energy density reaches $7.077 \mathrm{~J} / \mathrm{cm}^{2}$, only small amounts of $\mathrm{Fe}_{3} \mathrm{O}_{4}, \gamma-\mathrm{Fe}_{2} \mathrm{O}_{3}$, and $\gamma$-FeOOH can be observed. That may indicate that the corrosion has been removed well. Fourth, when the laser energy density reaches $8.493 \mathrm{~J} / \mathrm{cm}^{2}$, some new oxides appear. That can be observed by the increasing contents of $\alpha-\mathrm{Fe}_{2} \mathrm{O}_{3}, \gamma-\mathrm{FeOOH}, \gamma-\mathrm{Fe}_{2} \mathrm{O}_{3}$, and $\mathrm{Fe}_{3} \mathrm{O}_{4}$. Fifth, when the laser energy density climbs to $9.908 \mathrm{~J} / \mathrm{cm}^{2}$, the components of $\gamma-\mathrm{Fe}_{2} \mathrm{O}_{3}$ and $\mathrm{Fe}_{3} \mathrm{O}_{4}$ decrease or disappear. When the laser energy density becomes $11.323 \mathrm{~J} / \mathrm{cm}^{2}$, the amount of $\alpha-\mathrm{Fe}_{2} \mathrm{O}_{3}$ increases as well. From the results above, it can be seen that, regarding our application, the laser power outputs with the energy densities of $7.077 \mathrm{~J} / \mathrm{cm}^{2}$ or $8.493 \mathrm{~J} / \mathrm{cm}^{2}$ can get the comparable proper cleaning effects. Their subjective corrosion degrees are A (see Table 2). In our experiment, we do not find the $\beta-\mathrm{FeOOH}$ after cleaning. It may be explained that the $\beta$-FeOOH has been cleaned completely from the corrosion layer.

Table 11. The typical characteristic peaks of corrosion components in the research.

\begin{tabular}{ccc}
\hline$\alpha-\mathrm{Fe}_{2} \mathbf{O}_{3}$ & $\mathrm{Fe}_{3} \mathbf{O}_{4}$ & $\gamma-\mathrm{Fe}_{2} \mathbf{O}_{3}$ \\
\hline $220,293,404,495,612$ & $432,513,1322$ & $517,655,1580$ \\
\hline$\gamma-\mathrm{FeOOH}$ & $\alpha-\mathrm{FeOOH}$ & $\mathbf{F e O}$ \\
\hline $216,269,380,525,1307$ & 396,483 & 595 \\
\hline
\end{tabular}

Table 12. The peak and area fitting results of the Raman spectrum.

\begin{tabular}{|c|c|c|c|c|c|}
\hline \multicolumn{3}{|c|}{ Corrosion Degree B } & \multicolumn{3}{|c|}{ Corrosion Degree C } \\
\hline $\begin{array}{c}\text { Laser Energy } \\
\text { Density } \\
\left(\mathrm{J} / \mathrm{cm}^{2}\right)\end{array}$ & $\begin{array}{l}\text { Corrosion } \\
\text { Component }\end{array}$ & $\begin{array}{l}\text { Raman Shift } \\
\text { (peak area) }\end{array}$ & $\begin{array}{c}\text { Laser Energy } \\
\text { Density } \\
\left(\mathrm{J} / \mathrm{cm}^{2}\right)\end{array}$ & $\begin{array}{l}\text { Corrosion } \\
\text { Component }\end{array}$ & $\begin{array}{l}\text { Raman Shift } \\
\text { (peak area) }\end{array}$ \\
\hline \multirow{6}{*}{5.662} & $\alpha-\mathrm{FeOOH}$ & $\begin{array}{c}490.3 \\
(11,518.88) \\
392.8(2425.73)\end{array}$ & \multirow{6}{*}{5.662} & $\alpha-\mathrm{FeOOH}$ & $\begin{array}{c}466.9 \\
(12,997.08)\end{array}$ \\
\hline & $\gamma$-FeOOH & $\begin{array}{c}216.9(7401.40) \\
520.1(4482.71) \\
1301.1(98.98)\end{array}$ & & $\gamma$-FeOOH & $\begin{array}{c}212.2 \\
(10,467.41)\end{array}$ \\
\hline & $\alpha-\mathrm{Fe}_{2} \mathrm{O}_{3}$ & $282.8(8309.26)$ & & $\alpha-\mathrm{Fe}_{2} \mathrm{O}_{3}$ & $\begin{array}{c}497.5 \\
(38,790.21) \\
272.5 \\
(13,488.55)\end{array}$ \\
\hline & $\gamma-\mathrm{Fe}_{2} \mathrm{O}_{3}$ & $640.8(5231.48)$ & & $\gamma-\mathrm{Fe}_{2} \mathrm{O}_{3}$ & - \\
\hline & $\mathrm{Fe}_{3} \mathrm{O}_{4}$ & $1322.0(3007.09)$ & & $\mathrm{Fe}_{3} \mathrm{O}_{4}$ & $430.8(1125.86)$ \\
\hline & $\mathrm{FeO}$ & - & & $\mathrm{FeO}$ & - \\
\hline
\end{tabular}


Table 12. Cont.

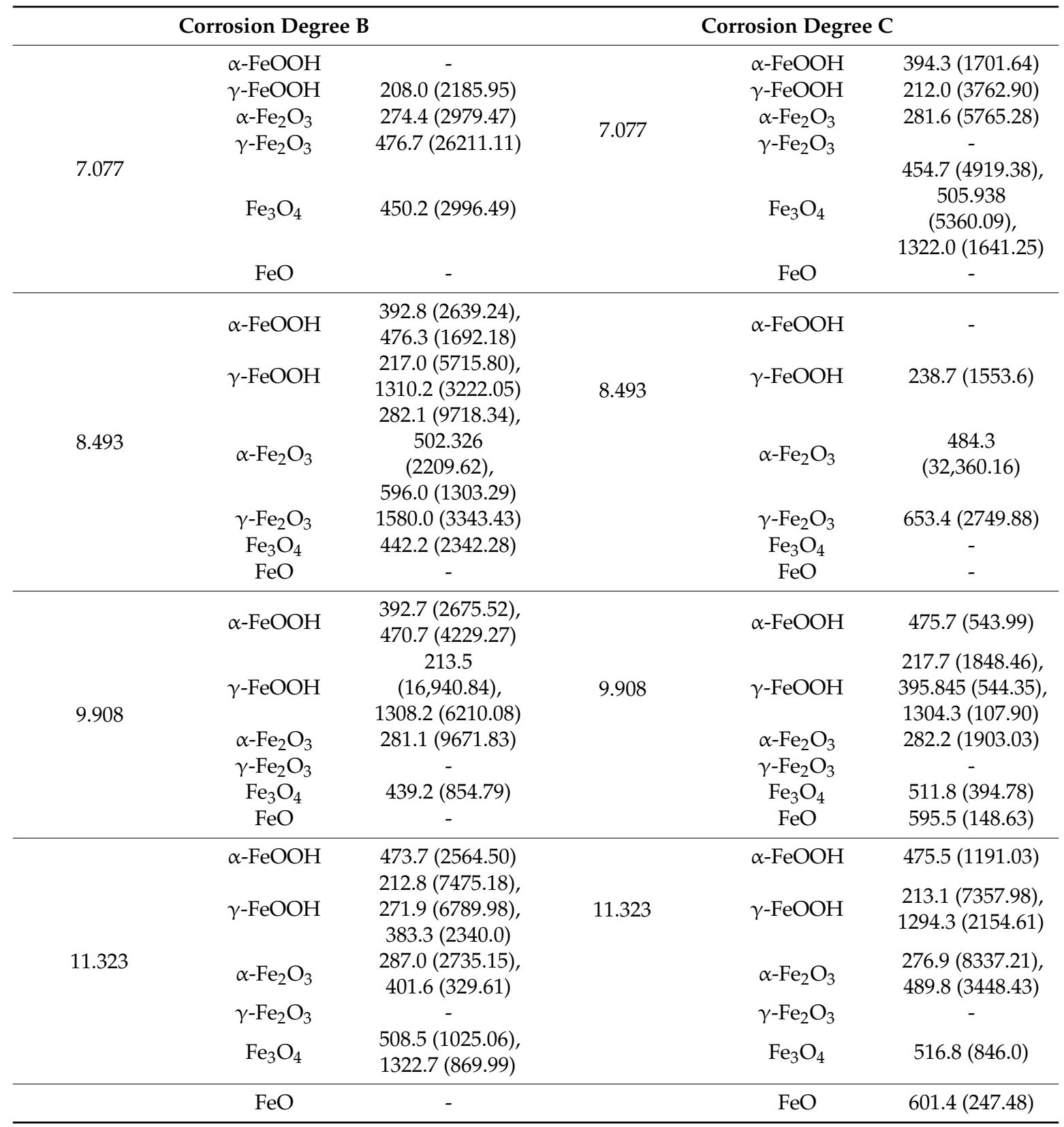

\subsection{Discussions}

In this paper, a kind of marine corrosion application is investigated. In general, the local corrosion, such as the interval or the gap, is easier to observe in the marine corrosion case. When the metal is immersed in the seawater, its corrosion types and amounts will change a lot with the lapse of time [34], and their colors will become darker and darker. In the early stage, the corrosions mainly belong to the pitting corrosions. It will distribute in the metal surface sporadically where the microscopic defects or scratches can be observed. Due to the chlorine element in the seawater, the components of corrosion mainly include $\gamma-\mathrm{FeOOH}$ and $\beta-\mathrm{FeOOH}$. Their colors would be faint yellow and tan. In the next stage, the corrosions become the rust spots. It will extensively distribute in the metal surface with some large areas. Most of the time, the corrosion will have a multi-layer [35]. The components in the surface layer is mainly $\gamma-\mathrm{FeOOH}$. While in the inner layer, they are $\mathrm{Fe}_{3} \mathrm{O}_{4}, \gamma-\mathrm{FeOOH}$, and $\beta-\mathrm{FeOOH}$. The colors of the corrosion layer would be reddish brown and brown. In the last stage, the corrosions become a thick corrosion layer. That means the surface of the metal will be covered by the corrosion layer completely. 
In addition, no metallic luster can be observed. The components of the corrosion layer are mainly $\beta-\mathrm{FeOOH}, \gamma-\mathrm{Fe}_{2} \mathrm{O}_{3}$, and $\mathrm{Fe}_{3} \mathrm{O}_{4}$. The colors of the corrosion layer are black and dark brown. When the laser cleaning method is utilized, the corrosion layer will be exfoliated from the metal surface. In the meantime, some oxides will also be created because of the thermal effect of the laser. However, most of the time, the contents of all kinds of oxides after laser cleaning should be smaller than the corrosion component contents before laser cleaning if the output power of the laser can be controlled properly.

To evaluate the effect of the laser power output on the Raman spectrum further, other comparison experiments are also performed. Figure 8 shows the experiment's results, which use different laser pulse widths and frequencies. Figure 8a illustrates a result using different laser pulse widths and Figure $8 \mathrm{~b}$ presents a result using different laser frequencies. Their main Raman peaks are also marked in this case. In Figure 8a, the pulse widths of 30 ns, 60 ns, 100 ns, 200 ns, and 400 ns are compared. In Figure 8b, the frequencies of $20 \mathrm{KHz}, 25 \mathrm{KHz}, 30 \mathrm{KHz}, 35 \mathrm{KHz}, 40 \mathrm{KHz}, 45 \mathrm{KHz}$, and $50 \mathrm{KHz}$ are considered. To improve the visualizing effects, all the vertical coordinates in Figure 8 a subtract 800 and the vertical coordinate increments in Figure $8 \mathrm{~b}$ are $0,100,200,-100,500,100$, and -100 , respectively. The pulse width [36] represents the maximum energy duration of the pulsed laser. The smaller the pulse width is, the bigger the laser energy output would be. The frequency [37] can reflect the pulse times of the laser in the unit time. The larger the frequency is, the bigger the laser output times would be. From Figure 8, it can be seen that the amounts of oxides are comparably low when the pulse width output is small. This is because the thermal effect is weak in this situation. In addition, with the increase of the pulse width, extra oxides appear. The result above means that the pulse width should not be too high when carrying out the cleaning task. Second, some oxides appear and their contents also increase plenty when the laser frequency becomes large. For example, the components $\mathrm{Fe}_{3} \mathrm{O}_{4}$, $\alpha-\mathrm{FeOOH}$, and $\alpha-\mathrm{Fe}_{2} \mathrm{O}_{3}$ can be observed with the increase of the frequency. In many practical cases, the pulse width and the frequency cannot be tuned during cleaning. Only the laser power can be changed sometimes, which also means they are not as important as the laser power from the practical application point of view. Thus, in this paper, we mainly consider the relationship evaluation between the laser power and the Raman spectrum.

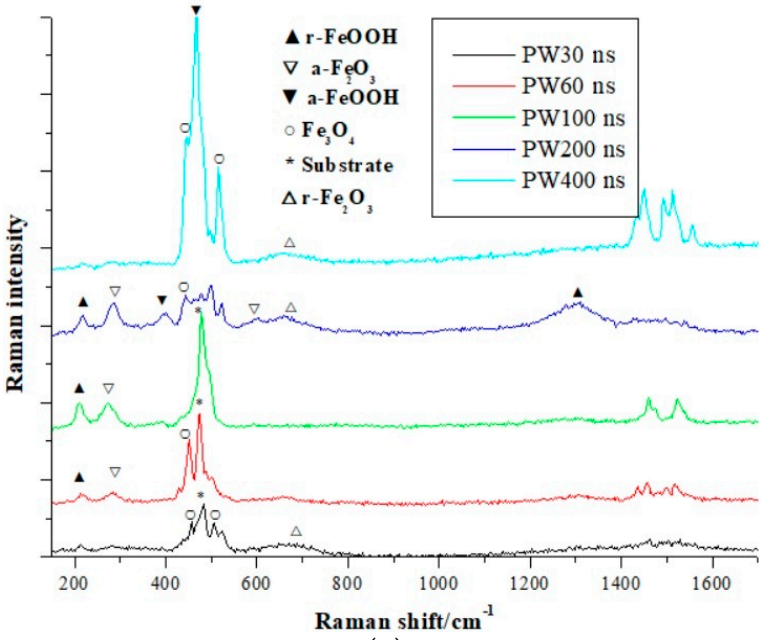

(a)

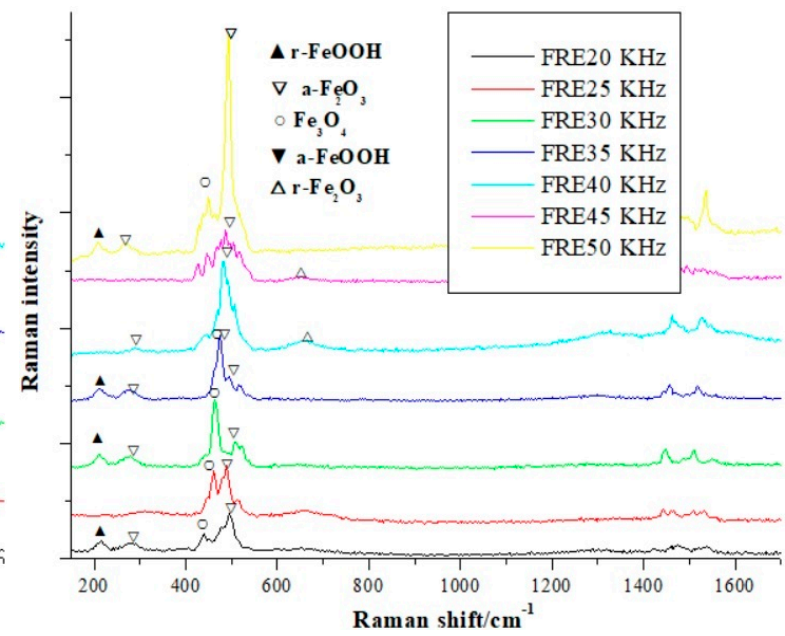

(b)

Figure 8. The Raman spectrum comparison using different pulse widths and frequencies. The abbreviation "PW" means the pulse width of the laser, and the abbreviation "FRE" is the laser frequency. (a) is the Raman spectrum comparison using the different pulse widths; (b) is the Raman spectrum comparison using the different frequencies.

In this paper, the ultimate cleaning target is to get a processed metal surface with the corrosion degree A (see Table 2), i.e., almost no corrosions can be observed directly in the metal surface. As a result, the Raman spectrum of the corrosion degree $\mathrm{A}$ is also investigated in this case. Figure 9 
shows the corresponding results. Figure $9 \mathrm{a}, \mathrm{b}$ are the Raman spectrum results of our investigated carbon steel. Their subjective corrosion degrees are A (see Table 2). To get these metal surfaces, the traditional physical-based and chemical-based cleaning methods are used including buffing and washing. From Figure 9, both the metal substrate [38,39] and different oxides, such as $\gamma-\mathrm{FeOOH}, \mathrm{Fe}_{3} \mathrm{O}_{4}$, and $\gamma-\mathrm{Fe}_{2} \mathrm{O}_{3}$, can be observed. The corresponding Raman peaks and their areas are also fitted by the Gaussian distribution function. Regarding Figure 9a, the peak shift of $\gamma-\mathrm{FeOOH}$ is $525.5 \mathrm{~cm}^{-1}$, and its peak area is 1433.7. The peak shift of $\mathrm{Fe}_{3} \mathrm{O}_{4}$ is $425.9 \mathrm{~cm}^{-1}$, and its area is 2779.3. The peak shifts of substrate are $471.0 \mathrm{~cm}^{-1}$ and $512.3 \mathrm{~cm}^{-1}$. Their areas are 35,042.3 and 10,827.7, respectively. As for Figure $9 \mathrm{~b}$, their peak shift of $\gamma-\mathrm{FeOOH}$ is $529.4 \mathrm{~cm}^{-1}$, and its peak area is 4154.9. The peak shift of $\gamma-\mathrm{Fe}_{2} \mathrm{O}_{3}$ is $514.0 \mathrm{~cm}^{-1}$, and its area is $34,388.1$. The peak shifts of the substrate are $461.9 \mathrm{~cm}^{-1}$ and $493.6 \mathrm{~cm}^{-1}$. Their areas are 75,234.0 and 34,936.7. In Figure 9, although the specific components in Figure 9a,b are different, their approximate Raman peak shapes are similar. Our proposed laser cleaning method can also get the cleaning effect of corrosion degree A (see Table 2). In this paper, compared with the laser cleaning effects illustrated in Figure 7, it can be seen that the laser energy densities of $5.662 \mathrm{~J} / \mathrm{cm}^{2}$ and $7.077 \mathrm{~J} / \mathrm{cm}^{2}$ with the initial corrosion degree B. The laser energy densities of $7.077 \mathrm{~J} / \mathrm{cm}^{2}$ and $8.493 \mathrm{~J} / \mathrm{cm}^{2}$ with the initial corrosion degree $C$ can get a similar cleaning effect like the results presented in Figure 9. The fact is that the practical situation is far more complex because of the diversity of the metal corrosion state. However, the analysis results of Figure 9 can still be looked on as a kind of reference for the cleaning effect evaluation in the future.

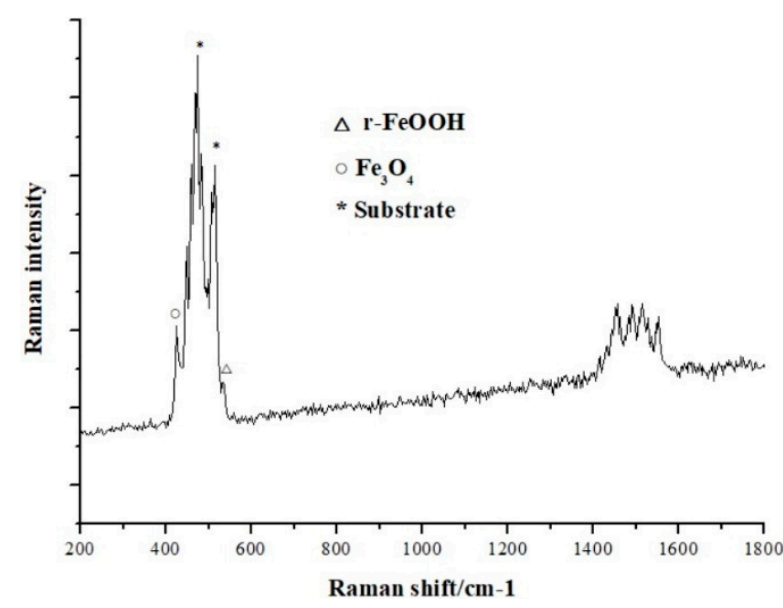

(a)

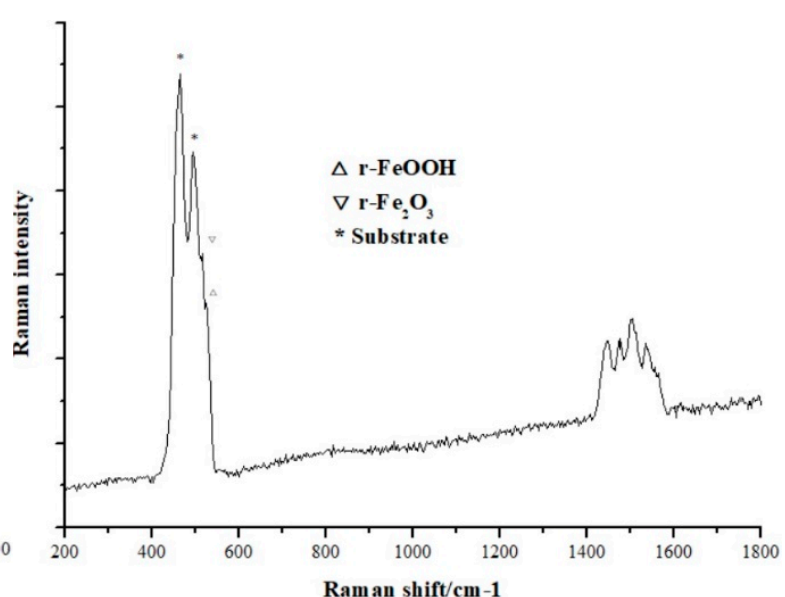

(b)

Figure 9. The Raman spectrum samples with corrosion degree A. (a) and (b) are the Raman spectrum samples after the traditional cleaning.

The corresponding research results above are useful for the practical engineering application. Figure 10 shows an example of the cleaning application. We can use the relationship above to generate a prediction map of the laser cleaning effect for the corrosion metal approximately. In Figure 10, the macroscopic photo of an original corrosion metal specimen is shown and the gray image is illustrated here. Figure $10 \mathrm{~b}$ is the mesh generation result of Figure 10a, where 24 meshes are generated and the shape of each mesh is square. In general, the size of each mesh should be similar to the photography size of the visible light camera. Figure 10c is the image-based evaluation result of the corrosion degree, where the green regions mean the corrosion degree $\mathrm{B}$ and the blue regions indicate the corrosion degree C (see Table 2). Figure 10d,e are the forecasted results of the Raman measurement, which use different laser energy density outputs, where Figure 10d uses the laser energy density of $7.077 \mathrm{~J} / \mathrm{cm}^{2}$ and Figure 10e employs the energy density of $8.493 \mathrm{~J} / \mathrm{cm}^{2}$. The yellow regions mean the Raman result with the corrosive component of $\mathrm{Fe}_{3} \mathrm{O}_{4}, \gamma-\mathrm{FeOOH}$, and $\gamma-\mathrm{Fe}_{2} \mathrm{O}_{3}$ while the brown regions indicate the Raman result with the corrosive component of $\alpha-\mathrm{Fe}_{2} \mathrm{O}_{3}, \gamma-\mathrm{FeOOH}$, and $\mathrm{Fe}_{3} \mathrm{O}_{4}$. From Figure 10, it can be seen that different predicted cleaning effects, i.e., the cleaning effect maps, can be obtained 
by using the corresponding experimental results above. Then these maps can be used to design the cleaning process and guide the secondary cleaning of the corrosive metal. It should be emphasized that the specific photography conditions (such as the environmental lighting and the photography distance, etc.) and the cleaning processes used in our experiment should be kept strictly when using this method above to implement the prediction.

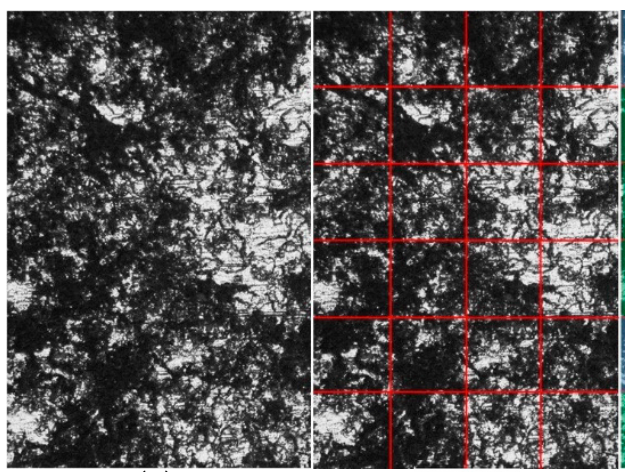

(a) (b)

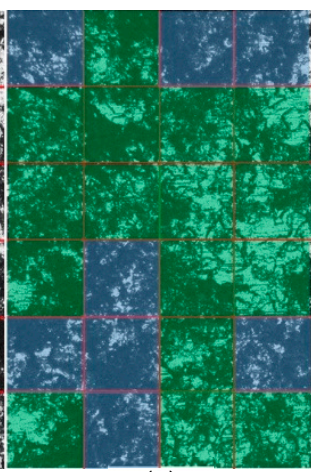

(c)

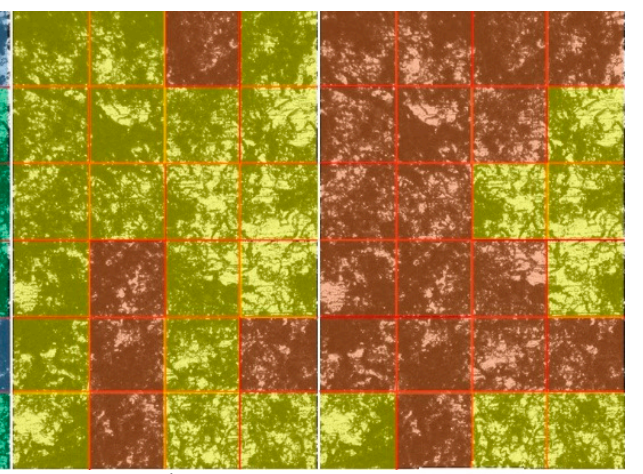

(d) (e)

Figure 10. The application example of the investigation results of our research work. (a) is the gray image of corrosion metal; (b) is the mesh generation result of $(\mathbf{a}) ;(\mathbf{c})$ is the corrosion degree evaluation result of $(\mathbf{b}) ;(\mathbf{d})$ is the cleaning prediction result using the energy density $7.077 \mathrm{~J} / \mathrm{cm}^{2}$; (e) is the cleaning prediction result using the energy density $8.493 \mathrm{~J} / \mathrm{cm}^{2}$.

Compared with other existing laser cleaning methods, our proposed research technique has three advantages. First, our method considers the initial corrosion state of the metal surface quantitatively. Although some research studies mentioned the initial corrosion issue [40-42], more of them [43,44] still did not consider the initial corrosion state problem when performing their research studies. Clearly, our research has indicated the initial corrosion will affect the cleaning effect to some extent. Second, our method uses the analysis results of the Raman spectrum to evaluate the cleaning effect. Like our proposed method in Section 2.1, the imaging sensor [45,46] can also be used to assess the processing effect after laser cleaning. However, because of multiple factors, such as the complex environment light or the exposed metal texture after cleaning, the computation accuracy of the imaging sensor will not be as good as that of the Raman spectrum. Third, our method utilizes the Gaussian distribution function to analyze the Raman spectrum data, and the corresponding results are more compelling. Many research studies [47,48] did not investigate the Raman spectrum by the distribution fitting-based technique. Thus, the estimated Raman results were not accurate in some cases. Our proposed method also has some shortcomings. For example, this method is not fit for solving the pitting corrosion issue. Since the proposed image analysis method can only process the macroscopic image with a big image texture, the pitting corrosion issue cannot be solved by this method currently. In the future, more corrosion images and their corresponding Raman spectrum data will be accumulated, and the processing effect of our proposed method can definitely be improved.

\section{Conclusions}

The relationships between the laser power output and the analysis result of Raman spectrum are investigated. First, an image feature analysis-based corrosion degree evaluation is proposed. The corresponding image features include texture coarseness, texture entropy, texture intensity, texture contrast, the texture's cluster degree, and texture homogeneity. Then the AHP method is used to decrease the dimension of the image feature vector for a convenient engineering application. Second, the laser cleaning operations, which use the typical power output, are performed under the defined initial corrosion degrees above. Then the Raman spectrum can be analyzed. The investigated parameters of the Raman spectrum include the corrosion components and their contents. The Savitzky-Golay filter-based method is employed to implement the baseline estimation. The Gaussian distribution-based 
method is utilized to carry out the peak area fitting. Lastly, the relationships between the laser power output and the Raman spectrum result can be constructed. The proposed methods and results can be used to guide the secondary cleaning of corrosion metal in the future.

Author Contributions: Conceptualization, H.L. and J.L. (Jinhui Lan). Data curation, Y.X. Formal analysis, H.L. Funding acquisition, H.L. Investigation, H.L. and Y.X. Methodology, H.L., Y.X., and J.L. (Jinhui Lan). Project administration, H.L. Resources, Y.X. and J.L. (Jinhui Lan). Software, J.L. (Jiacheng Li) and W.W. Supervision, H.L. Validation, H.L. and Y.X. Visualization, J.L. (Jiacheng Li) and W.W. Writing - original draft, H.L. Writing - review \& editing, H.L. All authors have read and agreed to the published version of the manuscript.

Funding: The Fund of State Key Laboratory of Intense Pulsed Radiation Simulation and Effect under Grant No. SKLIPR1713, the National Natural Science Foundation of China under Grant Nos. 61975011, 11775179, and the Fundamental Research Fund for the China Central Universities of USTB under grant No. FRF-BD-19-002A supported this work.

Conflicts of Interest: The authors declare no conflict of interest.

\section{References}

1. Kumar, A.; Biswas, D.J. Particulate size and shape effects in laser cleaning of heavy metal oxide loose contamination off clad surface. Opt. Laser Technol. 2018, 106, 286-293. [CrossRef]

2. See, T.L.; Metsios, I.; Qian, D.; Antar, M.; Marimuthu, S. Feasibility study and demonstration of cleaning with laser adaptively by novel use of sensors. Procedia CIRP 2018, 74, 376-380. [CrossRef]

3. Senesi, G.S.; Allegretta, I.; Porfido, C.; Pascale, O.D.; Terzano, R. Application of micro X-ray fluorescence and micro computed tomography to the study of laser cleaning efficiency on limestone monuments covered by black crusts. Talanta 2018, 178, 419-425. [CrossRef]

4. Liu, H.; Ma, Y.; Wang, W.; Yan, B. Non-destructive testing and assembly quality evaluation of IFOG optical path. J. Optoelectron Adv. Mater. 2019, 3-4, 171-179.

5. Li, J.; Liu, H.; Wu, W.; Yang, S.; Sheng, L. Corrosion assessment of carbon steel using texture and color features. In Proceedings of the IEEE 3rd International Conference on Electronic Information Technology and Computer Engineering, Xiamen, China, 18-20 October 2019; pp. 799-803.

6. Lee, W.-J.; Lee, S.-W. Improved spatiotemporal noise reduction for very low-light environments. IEEE T. Circuits-II 2016, 63, 888-892. [CrossRef]

7. Li, Q.; Lu, H.; Cui, J.; An, M.; Li, D. Electrodeposition of nanocrystalline zinc on steel for enhanced resistance to corrosive wear. Surf. Coat. Technol. 2016, 304, 567-573. [CrossRef]

8. Genna, S.; Lambiase, F.; Leone, C. Effect of laser cleaning in laser assisted joining of CFRP and PC sheets. Compos. Part B-Eng. 2018, 145, 206-214. [CrossRef]

9. Zou, J.; Chen, W.; Wan, F.; Fan, Z.; Du, L. Raman spectral characteristics of oil-paper insulation and its application to ageing stage assessment of oil-immersed transformers. Energies 2016, 9, 946. [CrossRef]

10. Beeskow-Strauch, B.; Schicks, J.M. The driving forces of guest substitution in gas hydrates-A laser Raman study on $\mathrm{CH}_{4}-\mathrm{CO}_{2}$ exchange in the presence of impurities. Energies 2012, 5, 420-437. [CrossRef]

11. Uhlmann, E.; Pontes, R.P.; Laghmouchi, A.; Bergmann, A. Concept of sustainable data for a selective laser melting machine. Procedia Manuf. 2018, 21, 655-662. [CrossRef]

12. Bonhoff, T.; Poppe, M.; Stollenwerk, J.; Schleifenbaum, J.H.; Loosen, P. Multi-physical analysis of thermos-optical effects for different selective laser melting (SLM) scanning strategies. Procedia CIRP 2018, 74, 97-101. [CrossRef]

13. Ao, S.; Luo, Z.; Zhao, N.; Bu, X.; Li, Y. Microphone arrays for acoustic detection during laser welding of cold-rolled steel strip. In Proceedings of the International Conference on Intelligent System Design and Engineering Application, Changsha, China, 13-14 October 2010; pp. 935-939.

14. Xiong, H.; Zhang, Y.; Chen, X.-W. Data-dependent kernel machines for microarray data classification. IEEE ACM Trans. Comput. Biol. Bioinforma. 2007, 4, 583-595. [CrossRef]

15. Zhan, H.; Luo, Z.; He, Z.; Lu, K. Tamura coarseness for evaluating OTH radar image and its application in RFI suppression. In Proceedings of the IEEE Radar Conference, Boston, MA, USA, 22-26 April 2019; pp. 1-6.

16. Yun, T.; Shu, H. Ultrasound image segmentation by spectral clustering algorithm based on the Curvelet and GLCM features. In Proceedings of the IEEE International Conference on Electrical and Control Engineering, Yichang, China, 16-18 September 2011; pp. 920-923. 
17. Asery, R.; Sunkaria, R.K.; Sharma, L.D.; Kumar, A. Fog detection using GLCM based features and SVM. In Proceedings of the Conference on Advances in Signal Processing, Pune, India, 9-11 June 2016; pp. 72-76.

18. Umaselvi, M.; Kumar, S.S.; Athithya, M. Color based urban and agricultural land classification by GLCM texture features. In Proceedings of the IET Chennai 3rd International on Sustainable Energy and Intelligent Systems, Tiruchengode, India, 27-29 December 2012; pp. 1-4.

19. Liang, X.; Li, L.; Cheng, G.; Gao, L. Underdeveloped village extraction from high spatial resolution optical image based on GLCM textures and fuzzy classification. In Proceedings of the 3rd International Workshop on Earth Observation and Remote Sensing Applications, Changsha, China, 11-14 June 2014; pp. 370-373.

20. Yaraghi, N.; Tabesh, P.; Guan, P.; Zhuang, J. Comparison of AHP and Monte Carlo AHP under different levels of uncertainty. IEEE Trans. Eng. Manag. 2015, 62, 122-132. [CrossRef]

21. Palomar, T.; Oujja, M.; Llorente, I.; Barat, B.R.; Canamares, M.V.; Cano, E.; Castillejo, M. Evaluation of laser cleaning for the restoration of tarnished silver artifacts. Appl. Surf. Sci. 2016, 387, 118-127. [CrossRef]

22. Pelosi, C.; Calienno, L.; Fodaro, D.; Borrelli, E.; Rubino, A.R.; Sforzini, L.; Monaco, A.L. An integrated approach to the conservation of a wooden sculpture representing Saint Joseph by the workshop of Ignaz Gunther (1727-1775): Analysis, laser cleaning and 3D documentation. J. Cult. Herit. 2016, 17, 114-122. [CrossRef]

23. Bloisia, F.; Baroneb, A.C.; Vicaria, L. Dry laser cleaning of mechanically thin films. Appl. Surf. Sci. 2004, 238, 121-124. [CrossRef]

24. Sabour, M.; Dezvareh, G.; Bazzazzadeh, R. Corrosion prediction using the weight loss model in the sewer pipes made from sulfur and cement concretes and Response Surface Methodology (RSM). Constr. Build Mater. 2019, 199, 40-49. [CrossRef]

25. Liu, L.; Tan, E.; Cai, Z.; Zhen, Y.; Yin, X. An integrated coating inspection system for marine and offshore corrosion management. In Proceedings of the International Conference on Control, Automation, Robotics and Vision, Singapore, 18-21 November 2018; pp. 1531-1536.

26. Schulze, H.G.; Foist, R.B.; Okuda, K.; Ivanov, A.; Turner, R.F.B. A small-window moving average-based fully automated baseline estimation method for Raman spectra. Appl. Spectrosc. 2012, 66, 757-764. [CrossRef]

27. Schettino, B.M.; Duque, C.A.; Silveira, P.M. Current-transformer saturation detection using Savitzky-Golay filter. IEEE Trans. Power Deliv. 2016, 31, 1400-1401. [CrossRef]

28. Gu, Z.; Chen, W.; Du, L.; Zou, J.; Long, Z. Analysis of methyl ethyl ketone dissolved in transformer oil using laser Raman spectroscopy. In Proceedings of the IEEE International Conference on High Voltage Engineering and Application, Chengdu, China, 19-22 September 2016; pp. 1-4.

29. Liu, H.; Lu, H. IQ evaluation based adaptive wavelet denoising and enhancement for a VRTAN system. In Proceedings of the IEEE/RSJ International Conference on Intelligent Robots and Systems, Nice, France, 22-26 September 2008; pp. 594-599.

30. Du, G.; Bi, S.; Xiao, Y.; Li, W. The compliance control study of Chinese chess robot in Cartesian coordinate system. In Proceedings of the International Conference on Advanced Mechatronic Systems, Luoyang, China, 25-27 September 2013; pp. 31-35.

31. Yang, C.; Hu, H.; Zhang, H. Modeling AOD-driven laser microvia drilling with machine learning approaches. J. Manuf. Process. 2018, 34, 555-565. [CrossRef]

32. Li, J.; Liu, J.; Jin, R.; Tang, Y.; Yue, S.; Wang, L.; Long, X.; Zhang, G.; Meng, Q.; Li, R. Quantitative measurement of artemisinin content in Chinese traditional compound medicine by Raman spectroscopy. Spectrosc. Spect. Anal. 2019, 39, 2403-2408.

33. Faria, D.L.A.D.; Silva, S.V.; Oliveira, M.T.D. Raman microspectroscopy of some iron oxides and oxyhydroxides. J. Raman Spectrosc. 1997, 28, 873-878. [CrossRef]

34. Chen, S.; Zhang, D. Corrosion behavior of Q235 carbon steel in air-saturated seawater containing Thalassospira sp. Corros. Sci. 2019, 148, 71-82. [CrossRef]

35. Wang, X.; Melchers, R.E. Corrosion of carbon steel in presence of mixed deposits under stagnant seawater conditions. J. Loss Prevent. Proc. 2017, 45, 29-42. [CrossRef]

36. Leng, X.; Yue, S.; Weng, Y.; Song, K.; Shi, Q. Effects of finite laser pulse width on two-dimensional electronic spectroscopy. Chem. Phys. Lett. 2017, 667, 79-86. [CrossRef]

37. Bruncko, J.; Sutta, P.; Netrvalova, M.; Michalka, M.; Vincze, A. Pulsed laser deposition of Ga doped ZnO films-Influence of deposition temperature and laser pulse frequency on structural, optical and electrical properties. Vacuum 2019, 159, 134-140. [CrossRef] 
38. Tserevelakisa, G.J.; Pozo-Antonioab, G.S.; Siozosa, P.; Rivasb, T.; Poulia, P.; Zacharakisa, G. On-line photoacoustic monitoring of laser cleaning on stone: Evaluation of cleaning effectiveness and detection of potential damage to the substrate. J. Cult. Herit. 2019, 35, 108-115. [CrossRef]

39. Pan, A.; Chiussi, S.; González, P.; Serra, J.; León, B. Comparative evaluation of UV-vis-IR Nd:YAG laser cleaning of beeswax layers on granite substrates. Appl. Surf. Sci. 2011, 257, 5484-5490. [CrossRef]

40. Marimuthu, S.; Mhich, A.; Molchan, I.S.; Whitehead, D.; Wang, Z.; Mativenga, P.; Li, L.; Liu, Z.; Grafton-Reed, C.; Cheetham, S.; et al. Numerical simulation of excimer laser cleaning of film and particle contaminants. J. Heat Transf. 2013, 135, 121301-1-121301-12. [CrossRef]

41. Lei, Z.; Sun, H.; Chen, Y.; Tian, Z. Elimination of rusting layer from high-strength steel surface using different laser cleaning methods. Chin. J. Lasers 2019, 46, 0702003-1-0702003-6.

42. Yue, L.; Wang, Z.; Li, L. Modeling and simulation of laser cleaning of tapered micro-slots with different temporal pulses. Opt. Laser Technol. 2013, 45, 533-539. [CrossRef]

43. Pozo-Antonio, J.S.; Papanikolaou, A.; Philippidis, A.; Melessanaki, K.; Rivas, T.; Pouli, P. Cleaning of gypsum-rich black crusts on granite using a dual wavelength Q-Switched Nd:YAG laser. Constr. Build. Mater. 2019, 226, 721-733. [CrossRef]

44. Striova, J.; Fontana, R.; Barucci, M.; Felici, A.; Marconi, E.; Pampaloni, E.; Raffaelli, M.; Riminesi, C. Optical devices provides unprecedented insights into the laser cleaning of calcium oxalate layers. Microchem. J. 2016, 124, 331-337. [CrossRef]

45. Pouli, P.; Zafiropulos, V.; Balas, C.; Doganis, Y.; Galanos, A. Laser cleaning of inorganic encrustation on excavated objects: Evaluation of the cleaning result by means of multi-spectral imaging. J. Cult. Herit. 2003, 4, 338-342. [CrossRef]

46. Shi, T.; Wang, C.; Mi, G.; Yana, F. A study of microstructure and mechanical properties of aluminum alloy using laser cleaning. J. Manuf. Process. 2019, 42, 60-66. [CrossRef]

47. Chen, Y.; Yan, X.; Zhang, X.; Shi, X.; Ma, J. Surface-enhanced Raman spectroscopy quantitative analysis of polycyclic aromatic hydrocarbons based on supports vector machine algorithm. Chin. J. Lasers 2019, 46, 0311005-1-0311005-8. [CrossRef]

48. Villa-Aleman, E.; Bridges, N.J.; Shehee, T.C.; Houk, A.L. Raman microspectroscopy of PuO2 particulate aggregates. J. Nucl. Mater. 2019, 515, 140-149. [CrossRef]

(C) 2019 by the authors. Licensee MDPI, Basel, Switzerland. This article is an open access article distributed under the terms and conditions of the Creative Commons Attribution (CC BY) license (http://creativecommons.org/licenses/by/4.0/). 